\title{
Aspectos Psicossociais da Depressão Pós-Parto: Uma Revisão Sistemática
}

\author{
Romenia Alves Ferreira Porto ${ }^{1}$; Thércia Lucena Grangeiro Maranhão ${ }^{2}$; Waleska Maria Félix ${ }^{3}$
}

Resumo: O presente artigo teve o objetivo de realizar uma Revisão Sistemática da Literatura sobre os aspectos psicossociais da depressão pós-parto no período de 2011 a 2016. A busca de dados foi feita nas bases de dados: Scielo, BVS, Pepsic e Pubmed. A pesquisa parte do interesse em compreender as prováveis alterações psicológicas e sociais acerca do conteúdo e contribuir na atualização do panorama geral de uma determinada área de interesse. A metodologia aplicada foi a revisão sistemática da literatura de cunho qualitativo. Foram selecionados 15 trabalhos que compuseram a amostra desta pesquisa. Os resultados encontrados apontaram para quatro eixos temáticos que foram alocados em categorias, são essas: Antecedentes da DPP; Aspectos psicossociais e epidemiológicos; Consequências da DPP e Políticas de intervenção. Observou-se que a maioria das pesquisas que compunham a amostragem dos artigos foram realizados empiricamente o que possibilita uma visão aplicada sobre as mulheres com DPP no Brasil. Sugere-se que as pesquisas futuras enfatizem as possíveis formas de tratamentos da DPP considerando a saúde coletiva.

Palavras-chave: Depressão. Pós-Parto. Aspectos Psicossociais.

\section{Psychosocial Aspects of Postpartum Depression: a Systematic Review}

\begin{abstract}
The present article aimed to perform a Systematic Review of Literature on the psychosocial aspects of postpartum depression in the period from 2011 to 2016. Data search was done in the databases: Scielo, BVS, Pepsic and Pubmed. The research starts from the interest in understanding the probable psychological and social changes about the content and contribute in the update of the general panorama of a certain area of interest. The methodology applied was the systematic review of qualitative literature. We selected 15 papers that composed the sample of this research. The results found pointed to four thematic axes that were allocated in categories, are these: History of PPD; Psychosocial and epidemiological aspects; Consequences of DPP and Intervention Policies. It was observed that most of the researches that compose the sampling of the articles were carried out empirically, which allows an applied view on women with PPD in Brazil. It is suggested that future research emphasize the possible forms of PPD treatment considering collective health.
\end{abstract}

Keywords: Depression. Post Childbirth. Psychosocial Aspects.

\section{Introdução}

Dentre os aspectos relacionados à atenção à saúde feminina, as circunstâncias do aparelho reprodutivo, especialmente na gravidez e no parto, tomaram destaque ao longo do tempo.

\footnotetext{
${ }^{1}$ Graduanda em Psicologia do Centro Universitário Doutor Leão Sampaio, Juazeiro do Norte-CE. Brasil. E-mail: romeniaporto@ hotmail.com ${ }^{2}$ Professora orientadora da Unileão, Psicóloga, graduada pela Faculdade de Ciências Humanas de Recife - ESUDA, Especialista em Gestão do Trabalho e da Educação na Saúde, pela Escola de Saúde Pública do Estado do Ceará. Aluna do programa de pós-graduação da Faculdade de Medicina do ABC, do curso de Mestrado em Ciências da Saúde. E-mail: thercia@leaosampaio.edu.br ${ }^{3}$ Graduação em Enfermagem pela Faculdade de Juazeiro do Norte.
} 
Id on Line Revista Multidisciplinar e de Psicologia

Id on Line Multidisciplinary and Psycology Journal

Durante o século XX, na década de 1970 e 1980 respectivamente, foram criados o Programa de Saúde Materno-Infantil (PMI) e o Programa de Assistência Integral à Saúde da Mulher - PAISM (STRAPASSON; NEDEL, 2010).

Estes programas surgiram com o objetivo de aprimorar a qualidade da saúde na atenção a este público. A fim de reforçar esta tentativa, implantaram em 2000, o Programa de Humanização no Pré-Natal e Nascimento (PHPN), com o objetivo de minimizar os números de morbimortalidade (mulheres com complicações durante a gestação e puerpério), aumentando o acesso ao pré-natal, além de melhorar a qualidade e humanização da atenção (BRASIL, 2002).

As questões referentes à saúde da mulher gestante, parto e pós-parto, ainda predominam nas discussões sobre aspectos da saúde e dos direitos das mulheres e seus filhos. Um dos motivos para que essa preocupação aconteça é o período puerperal, por sua peculiaridade é provável que em nenhuma outra fase haja tantas alterações no tocante ao funcionamento e a forma do corpo humano num período tão pequeno de tempo (SOUZA et al., 2002). É dentro deste cenário de mudanças que se desenvolvem alguns transtornos emocionais do pós-parto como a melancolia maternal (baby blues), a psicose puerperal e a depressão pós-parto (DPP) (FRIZZO; PICCININI, 2005). Neste trabalho, discute-se sobre a depressão pós-parto e os aspectos psicossociais a ela relacionados.

Segundo o DSM-IV, os sintomas da Depressão Pós-parto (DPP) são, no primeiro momento, a presença por no mínimo duas semanas de anedonia, a diminuição do interesse por coisas que eram interessantes, em outras situações, a mudança brusca no peso e apetite, cansaço, perda da concentração, insônia ou sono em excesso, agitação ou lentidão dos movimentos, sensação de desvalorização ou culpa e, em alguns casos, ideias suicidas. Estes sintomas ocorrem nas quatro primeiras semanas após o parto (DSM-IV, 1995).

A DPP tem ocorrência universal, apresentando uma incidência de $10 \%$ a $20 \%$, proporcionalmente um caso para cada 1000 mães. Em nosso país, uma pesquisa realizada em Pelotas-RS, divulgada em 2006,com a participação de 410 mulheres, destacou uma prevalência de 19,1\% da depressão pós-parto nesta mulheres.(MORAES et al., 2006) Outra pesquisa, dez anos depois e em nível nacional,foi divulgada contendo os relados de 23.896 mulheres entrevistadas no Brasil,que estavam no período de 6 a 18 meses após o nascimento dos filhos. 
Id on Line Revista Multidisciplinar e de Psicologia

Id on Line Multidisciplinary and Psycology Journal

A pesquisa apontou um índice de $26,3 \%$, isto é, cerca de uma em cada quatro brasileiras apresentavam sintomas da DPP (FOLHA DE SÃO PAULO, 2016).

Diferentemente do baby blues, que possui grande influência nas mudanças hormonais normais presentes no puerpério, a DPP não apresenta uma causa única. Enfatizando este dado, Silva et al. (2010) elenca os aspectos psicológicos, sociais e hormonais com influência direta no desenvolvimento da patologia, tais como: os antecedentes da depressão, o papel familiar na gestação e no puerpério, a presença de eventos estressores durante a gestação, as complicações na gravidez e no parto de risco.

Sendo assim, diante do interesse em compreender as prováveis alterações psicológicas e sociais acerca do conteúdo, da inquietação em compreender quais trabalhos estão sendo publicados sobre o tema na comunidade científica, este estudo se classifica como uma revisão sistemática, pois essas pesquisas são essenciais na atualização do panorama geral de uma determinada área de interesse.

Ante o exposto, surge a seguinte pergunta: quais os aspectos psicossociais da depressão pós-parto?

O objetivo principal deste trabalho foi realizar um Revisão Sistemática de Literatura sobre os aspectos psicossociais da depressão pós-parto dos últimos 5 anos, especificamente no período de 2011 a 2016. Teve como objetivos específicos: 1) Realizar uma busca de artigos sobre os aspectos psicossociais da depressão pós-parto nas bases de dados Scielo, BVS (Biblioteca Virtual em Saúde), Pepsic e PubMed; 2) Categorizar os artigos de acordo com o método de análise de conteúdo (BARDIN, 2002); 3) Descrever os principais eixos temáticos discutidos nos artigos científicos acerca dos aspectos psicossociais da depressão pós-parto; 4) Sugerir direcionamentos para as futuras pesquisas.

\section{Contextualizando a Depressão}

Os transtornos mentais estão sendo responsáveis por uma parte significante das situações patológicas e da mortalidade em todo o mundo. Os transtornos depressivos ocupam, neste contexto, o quarto lugar entre os mais influentes na estimativa mundial de doenças, sendo que 
Id on Line Revista Multidisciplinar e de Psicologia

Id on Line Multidisciplinary and Psycology Journal

poderá chegar ao segundo lugar nos próximos anos (LOBATO, MORAES, REICHENHEIM, 2011).

Nos últimos anos, os estudos enfatizam cada vez mais o fenômeno da depressão. $\mathrm{O}$ crescimento do debate sobre o tema tem feito com que a depressão fique conhecida como o "mal-do-século", sendo esta relacionada a alguns sofrimentos e sentimentos de perda. Pode ser considerada uma patologia pós-moderna, isto é, relacionada com as questões da contemporaneidade (CORRÊA; SERRALHA, 2015).

A depressão pode afetar pessoas do sexo masculino e do feminino em todo o mundo, no entanto há um predomínio de ocorrências no sexo feminino. As mulheres chegam a apresentar duas vezes mais risco que os homens, sendo que a maior incidência pode ser registrada na fase adulta, normalmente quando estas possuem filhos (LOBATO, MORAES, REICHENHEIM, 2011).

Estima-seque $20 \%$ das mulheres possam apresentar algum tipo de depressão ao longo da vida e é importante ressaltar que esta patologia impacta bastante na saúde não só da mulher, mas também na vida da família e daqueles com quem ela convive (CORRÊA; SERRALHA, 2015).

A grande prevalência de depressão no sexo feminino é a presença de eventos vitais importantes como a gravidez e o nascimento de um filho. Durante as fases de gravidez, parto e pós-parto, as mães vivenciam grande modificação da rotina e do estilo de vida, essas mudanças ainda estão atreladas à contínua tristeza e à diminuição da libido (SANTOS, 2001). Essas sensações são compreendidas como passageiras, mas caso não sejam trabalhadas podem se transformar em uma condição crônica.

Percebe-se que se tornar mãe traz consigo uma significativa carga depressiva, que faz contraponto ao mito popular que concebe a maternidade como uma situação prazerosa e apenas digna de felicidade para as mulheres (ARRAES; MOURÃO; FRAGALLE, 2014; CORRÊA; SERRALHA, 2015).

A depressão pós-parto tem uma incidência de até $20 \%$ no Brasil, no entanto quando se considera mulheres de classe econômica menos favorecida e que usam os serviços do Sistema Único de Saúde (SUS), este número pode ser bem maior, chegando a 40\% (ROSENBERG, 2007; LOBATO ET. AL., 2011). 
Id on Line Revista Multidisciplinar e de Psicoloqia

Id on Line Multidisciplinary and Psycology Journal

Outros estudos apontam os seguintes números para a prevalência em algumas cidades brasileiras: 12\% no Rio de Janeiro, 13,4\% em Brasília, 20,7\% em Porto Alegre, 26.9\% em Belo Horizonte e 7,2\% em Recife (SILVA ET. AL., 1998; SANTOS; MARTINS; PASQUALE, 1999; TANNOUS ET. AL., 2008; FIGUEIRA ET. AL., 2009; FIGUEIRA; DINIZ; SILVA FILHO, 2011).

Tais pesquisas mostraram que os números de depressão pós-parto no Brasil chegam a ser maiores aos apresentados em países de nível socioeconômico semelhante, o que tem contribuído para o aumento dos debates sobre esta patologia (ARRAES, MOURÃO, FRAGALLE, 2014).

Sendo assim, este trabalho vem fomentar ainda mais tais debates, visto que faz uma análise sistemática das produções acadêmicas sobre o tema, fazendo apontamentos sobre pesquisas e direcionamentos dos temas.

\section{Conceitos e Características da Depressão Pós-Parto}

Chama-se Depressão Pós-Parto o episódio marcado por perturbação emocional, humoral e reativa, que ocorre no período puerperal. São outras características da DPP: a queda da energia e da atividade, a diminuição da concentração, os distúrbios do sono, a presença de sentimentos de culpa e de baixa autoestima. De acordo com a maioria dos autores a DPP pode ser desencadeada por fatores específicos, mas em geral, apresenta características semelhantes aos outros casos depressivos (SANTOS; ALMEIDA; SOUZA, 2009; MORAES; FONSECA; DAVID; VIEGAS; OTTA, 2015).

Depressão pós-parto é o episódio depressivo vinculado à maternidade que acomete mulheres de todas as idades e de classes sociais após o episódio do parto. A DPP pode afetar também mulheres de todos os níveis de escolaridade, como também no caso de filhos desejados e não desejados, após o nascimento do primeiro filho ou dos demais (ARRAES, MOURÃO, FRAGALLE, 2014).

Observa-se em consideração o efeito que a idealização da gravidez e do bebê pode ocasionar na mãe e nos familiares, isto é, a criação de expectativas alegres com a chegada do 
Id on Line Revista Multidisciplinar e de Psicologia

Id on Line Multidisciplinary and Psycology Journal

bebê. No entanto, mediante os sentimentos ambivalentes, as dificuldades e as mudanças ocasionadas pela maternidade, tal idealização é chocada e a mãe ideal e perfeita passa a ser algo inalcançável para a mulher, o que pode trazer muitas frustrações e cobranças (CORRÊA; SERRALHA, 2015).

A Organização Mundial de Saúde (OMS, 2007) define que a DPP ocorre logo após o nascimento da criança e, para muitos autores, esta é a cronologia mais aceita. No entanto há quem estipule que os episódios de melancolia só podem ser considerados depressivos após duas semanas (antes disso trata-se do que se chama disforia puerperal ou melancolia da maternidade) e até três meses da ocorrência do parto, podendo ter sua ocorrência em meses. Nesta perspectiva, faz-se a diferenciação de melancolia da maternidade (ou disforia puerperal) da DPP, pois a primeira é considerada um distúrbio transitório e com grande contribuição hormonal (SANTOS ET AL., 2009; MORAES; FONSECA; DAVID; VIEGAS; OTTA, 2015).

Para Konradt et. al. (2011), pode-se considerar, na DPP, os episódios depressivos que ocorrem em até um ano após o parto. Segundo os autores, os doze meses após o parto são marcados por alterações hormonais e modificações no caráter social, na forma que a família se organiza e na maneira como a mulher se identifica. A DPP, nesta perspectiva, também pode ter sua duração em meses e pode apresentar os intensos sintomas presentes nas outras formas de depressão, abalando também a funcionalidade da mulher em relação às atividades rotineiras.

Sousa, Prado e Piccinini (2011) trazem outra característica cronológica sobre o início dos sintomas da DPP: a definição de Klaus, Kennel, Klaus (2000) afirma que os sintomas depressivos surgem entre a quarta e a oitava semana após o parto, considerando a patologia. Os autores também têm o mesmo ponto de vista sobre a sintomatologia, acrescentando apenas os sentimentos de desamparo, de desesperança e de incapacidade, além de transtornos alimentares.

Além da definição e das características da DPP, outro quesito que também é importante, para considerar a sua análise: os fatores de risco ou preditores. A vivência de alguns eventos negativos pelas mulheres pode influenciar no desenvolvimento da patologia, isto é, podem aumentar o grau de tensão, deixando-as vulneráveis fisicamente, socialmente e emocionalmente (MORAES ET. AL., 2006).

No tocante aos fatores de risco da DPP, Kohradt et. al. (2011) traz a vivência de ocasiões estressoras, da relação conflituosa com o parceiro, da falta de suporte social, e familiar, 
Id on Line Revista Multidisciplinar e de Psicologia

Id on Line Multidisciplinary and Psycology Journal

depressões e da ocorrência de ansiedade durante a gestação e a história de depressão na família como eventos significativos.

Também podem ser considerados fatores de risco para o desenvolvimento da DPP uma relação ruim com a mãe (referência de maternidade para as mulheres), eventos estressantes na gravidez como ameaça de aborto, o parto, a exemplo de complicações envolvendo risco de vida da mãe ou bebê, e também as situações econômicas da mãe e da família (ARRAES, MOURÃO, FRAGALLE, 2014).

É importante ressaltar que, apesar das divergências dos autores em relação a alguns pontos, deve-se considerar a subjetividade e especificidade do sujeito, isto é, de cada mulher e de como estas vivenciam, de formas variadas, o processo de gravidez, parto e pós-parto.

Apesar de tantas definições e de diversas características apontadas, é essencial pontuar que este trabalho se volta para a análise da diversidade de trabalhos publicados, sendo assim, todas as definições e as caracterizações que envolvam o fenômeno da DPP são importantes e foram levados em consideração na revisão sistemática.

\section{Consequências da DPP}

Como colocado, a DPP é um evento que afeta não só a mulher, mas toda a sua família. De acordo com alguns autores, os principais impactos estão na relação da mãe com o bebê. Sousa, Prado e Piccinini (2011) revelam que este impacto está recebendo cada vez mais atenção das pesquisas, no tocante ao tema de desenvolvimento infantil nos últimos anos. Boa parte dos estudos realizados neste sentido dá destaque à como as implicações da ocorrência da DPP na mãe pode afetar a qualidade da relação mãe-bebê, e posteriormente no desenvolvimento da criança.

O primeiro fato se dá nos cuidados mais básicos com a criança, que de acordo com a literatura, são extremamente significativos, pois são eles que permitem que a relação mãe-bebê seja permeada através do afeto. Por causa da debilidade emocional e física, a mãe fica incapacitada de realizar estes cuidados (como amamentar, trocar fraldas, dar banho, etc.) de maneira positiva e dispondo de contato emocional (FIGUEIRA; DINIZ; FILHO, 2011). 
Em um estudo realizado por Carlesso, Sousa e Moraes (2014), evidenciou-se que as mães com depressão pós-parto não conseguiam lidar com as demandas dos bebês quando estes choravam, por exemplo. O estudo mostra que as mães que possuem os sinais de DPP podem estar dispersas, irritadas e, por isso, não conseguem identificar os sinais que o bebê emite (se o bebê chora de dor, fome, etc.). Neste caso, há o comprometimento da comunicação entre a mãe e a criança, prejudicando também a interação entre ambos.

A incapacidade de a mãe em prestar estes cuidados fundamentais é um dos fatores que levam as mulheres com DPP a pararem de amamentar seus filhos antes do prazo de seis meses, afetando negativamente também a qualidade da amamentação (MACHADO ET. AL, 2014).

É importante frisar que o desenvolvimento da criança depende da mediação de um adulto, isto é, o bebê vai necessitar de alguém que possa cuidar e promover sua interação com o ambiente. Sabe-se que a situação em que se encontra a mãe e seus familiares pode afetar diretamente este cuidado e esta mediação, ou seja, um ambiente onde a criança não tenha este auxílio poderá afetar de forma negativa o desenvolvimento do bebê (CARLESSO, SOUSA, MORAES, 2014).

Observa-se, então, o quanto a DPP pode influenciar negativamente a mãe, o bebê e a dinâmica familiar ao todo.

\section{Considerações sobre o Tratamento da DPP}

O diagnóstico precoce, assim como o tratamento adequado contribuem fervorosamente para uma recuperação rápida da condição, além de diminuir as consequências prejudiciais à mãe, ao bebê e à estrutura familiar. No entanto, apesar dos grandes números de casos de DPP registrados, o tratamento ainda é um desafio (FIGUEIRA; DINIZ; FILHO, 2011).

$\mathrm{Na}$ atenção primária à saúde do Brasil há o registro de dificuldades no tratamento da DPP, apesar de haver medidas eficientes para a identificação e o tratamento. Este fato fez com que o Ministério da Saúde lançasse uma medida que priorizada a triagem e o acompanhamento das crianças e das mulheres durante o pós-parto. (ROJAS ET. AL., 2007). 
Martinez, Vöhringer e Rojas (2016) promoveram um estudo que objetivava desenvolver um modelo preditivo dos fatores que podem dificultar o acesso ao tratamento da DPP nas mulheres mães que utilizam os serviços da Atenção Primária à Saúde (APS). Os resultados desta pesquisa evidenciaram que os baixos níveis de anedonia, ansiedade e a falta de episódios depressivos na história de vida das mulheres podem determinar o não acesso de mulheres ao tratamento de DPP na APS.

Isto é, a falta de um indício anterior acarreta a não importância dada a alguns sintomas, por serem mais suaves, e isso faz com que haja uma dificuldade no tratamento de boa parte das mulheres com DPP atualmente. Este fato faz com que a identificação precoce da DPP não ocorra e suas consequências sejam maiores sobre a mãe, a criança e a família.

Então, apesar dos sintomas mais agudos de DPP interferirem de forma mais grandiosa nos processos importantes do inicio da relação mãe-bebê, as representações mais brandas destes sintomas também são bastante preocupantes, pois dificulta a identificação e o tratamento, podendo recorrer no seu agravamento.

\section{Procedimentos Metodológicos}

O método utilizado para realizar esta pesquisa foi a revisão sistemática da literatura. Para Galvão e Pereira (2014), a revisão sistemática possibilita uma investigação voltada a um problema bem definido, visando identificar, selecionar, avaliar e sintetizar os resultados relevantes encontrados. Além disso, as revisões sistemáticas da literatura seguem um processo rigoroso de construção, o que permite que sejam reproduzidas por outros pesquisadores. Este trabalho se propôs a uma de revisão sistemática da literatura dos últimos cinco anos (2011 2016).

Sobre a revisão sistemática da literatura CDR se tem a Report (KHAN, TER RIET, GLANVILLE, SOWDEN, KLEIJNEN, 2000), que recomenda as etapas a se seguir: 1) Elaboração de uma pergunta problema que elaborará conclusões; 2) A forma de seleção das fontes de estudos na pesquisa; 3) Análise do conteúdo dos artigos selecionados pelos resumos e pelas palavras-chave; 4) Conferência das informações, em conformidade com os objetivos 
Id on Line Revista Multidisciplinar e de Psicologia

Id on Line Multidisciplinary and Psycology Journal

propostos; 5) Interpretação relativa de eixos temáticos relacionados com os objetivos; 6) Atualização da temática, de forma a proporcionar novas críticasłsugestões, contribuindo assim com estudos subsequentes (GALVÃO; PEREIRA, 2014; SAMPAIO; MANCINI, 2007).

A pergunta de partida utilizada no presente estudo foi: Quais os aspectos psicossociais da depressão pós-parto?

Para alcançar este fim, foi realizada busca de artigos científicos por meio dos descritores: Depressão Pós-Parto, Depressão Puerperal e Depressão Pós Natal. Estes estão disponíveis nas bases de dados: Scielo (Scientific Electronic Library Online), BVS (Biblioteca Virtual em Saúde), Pepsic e PubMed. Inicialmente, utilizou-se a triagem dos artigos por seus títulos e resumos. Foram coletados trabalhos que contivessem as palavras-chave: depressão, pós-parto e aspectos psicossociais. A seleção do banco de dados se deu por se tratar de fontes seguras e mais utilizadas para pesquisas científicas no país.

O Scielo é base de dados eletrônica parceira do BIREME- Centro Latino_americano e do Caribe de Informação em Ciências da Saúde, foi desenvolvida pela FAPESP - Fundação de Amparo à Pesquisa de São Paulo. Sua qualidade é atestada pelo CNPQ - Conselho Nacional de Desenvolvimento Científico e Tecnológico. Possui a metodologia de armazenamento eletrônico com um rico acervo, permitindo a análise da situação da temática estudada neste artigo dentro do período de tempo determinado acima. Possibilita, ainda, uma maior compreensão dos subtemas mais discutidos (OLIVEIRA ET. AL., 2015).

O PePSIC (Periódicos Eletrônicos de Psicologia) é uma fonte da Biblioteca Virtual em Saúde - (BVS-Psi ULAPSI) - e uma parceria do FENPB, a Biblioteca Dante Moreira Leite do Instituto de Psicologia da Universidade de São Paulo (IP/USP). Já o PubMed é outra base de dados utilizada para artigos científicos. Esta conta com mais de 17 milhões de artigos, e é coordenada pela Biblioteca Nacional de Medicina dos Estados Unidos da América (National Library of Medicine). O PubMed é a versão gratuita da Medline (Medical Literature Analysis and Retrieval System Online), base de dados americana que abriga cerca de 18 milhões de títulos de jornais científicos em diversas áreas como biomedicina, enfermagem, odontologia, veterinária, psicologia, dentre outros (OLIVEIRA ET. AL., 2015).

Para selecionar estes trabalhos foi utilizada, como técnica, a busca pelas palavras-chave. À medida que apareciam na busca eletrônica, os artigos repetitivos foram catalogados apenas 
uma única vez. Os artigos foram escolhidos e foi aplicado o método de Análise de Conteúdo Temática (BARDIN, 2002), para categorizar os trabalhos e dando sentido a amostra colhida. Agrupou-se por semelhança dos principais temas tratados dentro do tema maior proposto.

Bardin (2002) enfatiza que a análise de conteúdo é um processo sistemático que utiliza a descrição do conteúdo e da mensagem com o objetivo de inferir dados de conhecimentos existentes na literatura. Para o autor, a intenção é conseguir indicadores que auxiliem na interpretação dos conhecimentos das mensagens. Desta forma, a análise de conteúdo é uma técnica de análise de comunicações. Esta informação pode ser conteúdos de figuras de linguagem, reticências, entrelinhas, quanto dos manifestos.

Neste trabalho se considerou inicialmente a análise do conteúdo dos títulos e/ou das frases nos artigos. Os resumos e as citações presentes no texto também foram levados em consideração na análise. Assim como orienta a literatura, inicialmente foi realizada uma leitura flutuante dos artigos,após foi feita uma leitura mais criteriosa, na qual se permitiu uma compreensão mais precisa das informações. Posteriormente, os textos foram separados em categorias (OLIVEIRA et. al., 2015).

Os critérios de inclusão utilizados nesta pesquisa foram: a) artigos completos e originais; b) revisões de literatura, estudos transversais, pesquisa de campo exploratória e estudos de corte prospectivos e retrospectivos; c) artigos em língua portuguesa; d) artigos que continham uma ou mais das palavras-chave no título ou no resumo; e) estudos a partir de 2011; f) dissertações de mestrado.

Já os critérios de exclusão foram: a) estudos feitos com animais; b) estudos anteriores a 2011; c) editoriais e cartas ao editor; d) relatos de casos, séries de casos ou de caso-controle; e) estudos de revisão que não abordem o assunto estudado.

Foram encontrados 47 artigos, dos quais 15 foram selecionados para formar a amostra de revisão do presente trabalho, pois estavam dentro dos critérios de inclusão. 
Id on Line Revista Multidisciplinar e de Psicologia

Id on Line Multidisciplinary and Psycology Journal

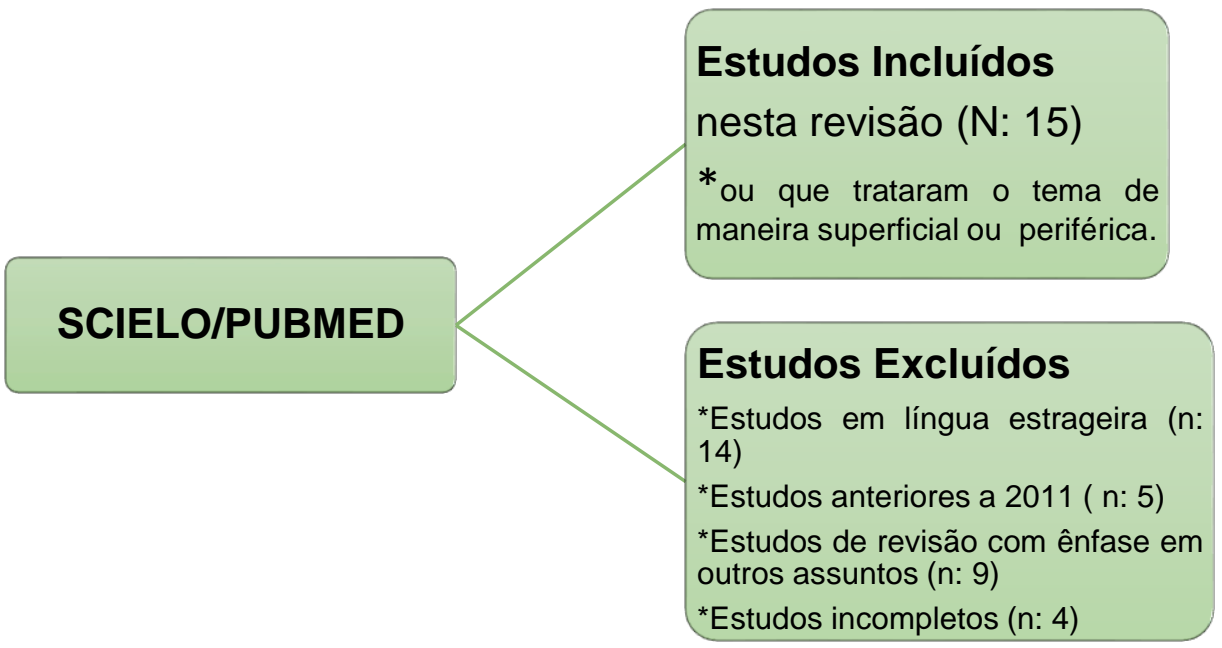

Figura 1: Fluxograma demonstrativo da seleção dos estudos.

A tabela 1, apresenta a lista dos 15 artigos considerados, a partir da triagem pelos critérios de inclusão e exclusão.

Tabela 1 - Artigos selecionados para este estudo (2016)

\begin{tabular}{|c|c|}
\hline ARTIGOS & CATEGORIA \\
\hline 1. RODRIGUES; SCHIAVO, 2011 & 1 \\
\hline 2. AIROSA; SILVA, 2013 & 1 \\
\hline 3. CORRÊA; SERRALHA, 2015 & 1 \\
\hline 4. LOBATO; MORAES; REICHENHEIM, 2011 & 2 \\
\hline 5. MORAES et. al., 2015 & 2 \\
\hline 6. KONRADT et. al., 2011 & 2 \\
\hline 7. SOUSA; PRADO; PICCININI, 2011 & 2 \\
\hline 8. FIGUEIRA; DINIZ; SILVA FILHO, 2011 & 2 \\
\hline 9. FIGUEIREDO et. al., 2013 & 2 \\
\hline 10. CARLESSO; SOUZA; MORAES, 2014 & 3 \\
\hline 11. MACHADO et. al., 2014 & 3 \\
\hline 12. ALVES, FONSECA, CANAVARRO; PEREIRA, 2016 & 3 \\
\hline 13. MARTÍNEZ; VÖHRINGER; ROJAS, 2016 & 4 \\
\hline 14. ARRAIS; MOURÃO; FRAGALLE, 2014 & 4 \\
\hline 15. SCHARDOSIM; HELDT, 2011 & 4 \\
\hline
\end{tabular}


Id on Line Revista Multidisciplinar e de Psicologia

Id on Line Multidisciplinary and Psycology Journal

\section{Resultados e Discussão}

\section{Análise das Informações e das Categorias Elencadas}

Dos 15 artigos selecionados, seis artigos foram de 2011, dois do ano de 2013; três do ano de 2014; dois do ano de 2015 e dois do ano de 2016, demonstrando que ocorreu inicialmente uma considerável queda de publicações, logo após manteve-se constância. Observe-se no gráfico a seguir:

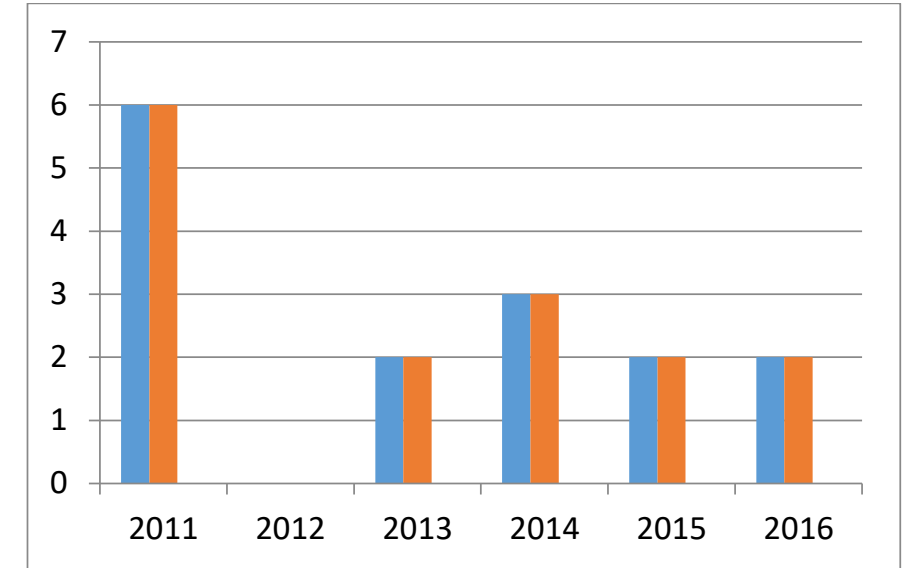

Quadro 1 - Gráfico da distribuição dos artigos selecionados por ano.

Fonte: AUTORIA, 2016.

Percebe-se que há uma queda significativa nas publicações no ano de 2012, mantendo a constância nos anos seguintes. A maior concentração de trabalhos está localizada no ano de 2011 e 2014.

No tocante a autoria dos trabalhos encontrados, observou-se que em sua totalidade há a presença de mais de um autor, sendo que a maioria das produções possuem três autores.

Os assuntos discutidos foram agrupados em 4 categorias: Categorias:1 - Antecedentes da depressão pós-parto (3 artigos - 20\%); 2 - Fatores psicossociais e epidemiológicos (6 artigos - $40 \%) ; 3$ - Consequências da depressão pós-parto (3 artigos - 20\%); 4 - Políticas de intervenção (3 artigos - 20\%). As categorias foram definidas a partir das prevalências e das 
Id on Line Revista Multidisciplinar e de Psicologia

Id on Line Multidisciplinary and Psycology Journal

expressões encontradas nas buscas realizadas nas bases de dados Scielo, BVS, Pepsic e Pubmed.

\section{Categoria 1 - Antecedentes da depressão pós-parto}

Nesta categoria foram enquadrados os trabalhos que teceram sobre os antecedentes da depressão pós-parto.

Para este trabalho serão considerados antecedentes da depressão pós-parto conteúdos literários referentes a eventos e a condições que fizeram parte da história de vida de mulheres diagnosticadas com depressão pós-parto, que foram relacionados com o desenvolvimento da psicopatologia.

A tabela 2 compõe a exposição dos dados e as características apresentadas nos estudos selecionados pelos critérios de inclusão para a Categoria 1:

Tabela 2- Artigos da Categoria 1 - Antecedentes da depressão pós-parto (2016).

\begin{tabular}{|c|c|c|c|c|}
\hline Autor/Tema & Periódico/ Ano & $\begin{array}{l}\text { Tipo de } \\
\text { estudo }\end{array}$ & Amostra & Objetivos e Achados da Pesquisa \\
\hline $\begin{array}{l}\text { RODRIGUES, Olga } \\
\text { Maria Piazentin } \\
\text { Rolim e; SCHIAVO, } \\
\text { Rafaela de Almeida. } \\
\text { Stress na gestação e } \\
\text { no puerpério: uma } \\
\text { correlação com a } \\
\text { depressão pós-parto. }\end{array}$ & $\begin{array}{l}\text { Rev. Brasileira de } \\
\text { Ginecologia e } \\
\text { Obstet. } 2011 .\end{array}$ & $\begin{array}{l}\text { Exploratório } \\
\text { Descriti-vo. }\end{array}$ & $\begin{array}{l}1 \text { etapa:98 } \\
\text { primigestas } \\
\text { usuárias do } \\
\text { Sistema Único de } \\
\text { Saúde (SUS). } \\
2 \text { etapa: } 64 \\
\text { primigestas } \\
\text { usuárias do } \\
\text { Sistema Único de } \\
\text { Saúde (SUS). }\end{array}$ & $\begin{array}{l}\text { Descreveu e comparou as fases } \\
\text { do stress de primigestas no } \\
\text { terceiro trimestre de gestação e } \\
\text { no pós-parto e } \\
\text { correlacioná-las à ocorrência de } \\
\text { depressão pós-parto (DPP). Os } \\
\text { significativos de stress na } \\
\text { gestação foram superiores à } \\
\text { frequência apresentada } \\
\text { no puerpério. Houve correlação } \\
\text { entre o stress tanto da gestação } \\
\text { como no puerpério e a } \\
\text { manifestação de DPP }(\mathrm{p}<0,001) \text {. }\end{array}$ \\
\hline $\begin{array}{l}\text { AIROSA, Sara e; } \\
\text { SILVA, Isabel. } \\
\text { Associação entre } \\
\text { vinculação, } \\
\text { ansiedade, } \\
\text { depressão, estresse e }\end{array}$ & $\begin{array}{l}\text { Psicologia, saúde e } \\
\text { doenças, } 2013 .\end{array}$ & $\begin{array}{l}\text { Exploratório } \\
\text { Descriti-vo. }\end{array}$ & $\begin{array}{l}100 \text { mulheres, das } \\
\text { quais } 50 \mathrm{se} \\
\text { encontraram no } \\
\text { período }\end{array}$ & $\begin{array}{l}\text { Buscou-se analisar se existe } \\
\text { uma associação entre suporte } \\
\text { social, sintomatologia } \\
\text { depressiva, ansiosa e stresse, e a } \\
\text { vinculação. Os dados }\end{array}$ \\
\hline
\end{tabular}




\begin{tabular}{|c|c|c|c|c|}
\hline $\begin{array}{l}\text { suporte social na } \\
\text { maternidade. }\end{array}$ & & & $\begin{array}{l}\text { gestacional e as } \\
\text { restantes na fase } \\
\text { do pós-parto. }\end{array}$ & $\begin{array}{l}\text { permitiram verificar que o } \\
\text { suporte social está } \\
\text { negativamente relacionado } \\
\text { com a ansiedade, depressão e } \\
\text { stresse e positivamente } \\
\text { relacionado com a vinculação } \\
\text { materna. Também se constatou } \\
\text { existir uma associação } \\
\text { negativa entre ansiedade, } \\
\text { depressão e stresse, e a } \\
\text { vinculação mãe-bebê. }\end{array}$ \\
\hline $\begin{array}{l}\text { CORRÊA, Fernanda } \\
\text { Pavão e; } \\
\text { SERRALHA, } \\
\text { Conceição } \\
\text { Aparecida. A } \\
\text { depressão pós-parto } \\
\text { e a figura materna: } \\
\text { uma análise } \\
\text { retrospectiva e } \\
\text { contextual. }\end{array}$ & $\begin{array}{l}\text { Acta Colombiana } \\
\text { de Psicología, } 2015 .\end{array}$ & $\begin{array}{l}\text { Exploratório } \\
\text { Descriti-vo }\end{array}$ & $\begin{array}{l}\text { Cinco mães que } \\
\text { foram acometidas } \\
\text { pela depressão } \\
\text { pós-parto em } \\
\text { algum momento } \\
\text { de suas vidas. }\end{array}$ & $\begin{array}{l}\text { Pretendeu buscar na fala de } \\
\text { mulheres que foram } \\
\text { acometidas pela depressão pós- } \\
\text { parto, vivências em relação à } \\
\text { maternidade que tiveram com } \\
\text { suas próprias mães, e verificar } \\
\text { se essas vivências influenciaram } \\
\text { no desencadeamento da } \\
\text { depressão. Os resultados } \\
\text { evidenciaram que a maioria } \\
\text { das participantes demonstrou } \\
\text { relação conflituosa com suas } \\
\text { mães, com indícios de que os } \\
\text { modelos de mulher/mãe que } \\
\text { foram vivenciados tiveram } \\
\text { influência no desencadeamento } \\
\text { e agravamento da depressão } \\
\text { pós-parto. }\end{array}$ \\
\hline
\end{tabular}

Quando se pretende levantar dados sobre os aspectos psicossociais da depressão pósparto é relevante pontuar sobre os fatores que estão presentes durante a gravidez e o puérperio, analisando como estes podem participar na eclosão da situação depressiva após o parto. Nos trabalhos analisados, nesta categoria, foram pontuados os eventos estressores, a relação de vinculo, a ansiedade, a depressão, o suporte social com a depressão pós-parto, assim como as vivências das mães com suas próprias figuras maternas.

De acordo com Rodrigues e Schiavo (2011) e Corrêa e Serralha (2015) os elementos de risco da depressão pós-parto são: o histórico de depressão anterior, a falta de apoio social e familiar, os problemas conjugais, as complicações na gestação, as dificuldades financeiras, a baixa idade e escolaridade, o desemprego, a dependência de substâncias químicas, a violência doméstica e a gravidez não planejada e rejeitada. 
Id on Line Revista Multidisciplinar e de Psicologia

Id on Line Multidisciplinary and Psycology Journal

\section{Categoria 2 - Fatores psicossociais e epidemiológicos}

Na categoria 2 estão os trabalhos que trouxeram no seu corpo teórico aspectos a temática sobre os fatores psicossociais e epidemiológicos identificados no processo de DPP.

Sendo assim, são considerados fatores psicossociais/epidemiológicos da DPP os conteúdos literários que englobam a situação psicológica e o estado social das mulheres acometidas com a DPP, assim como algumas características estatísticas referentes à classe social, à idade, ao nível de escolaridade e etc.

Na tabela 3, observa-se a exposição dos trabalhos selecionados a partir dos critérios de inclusão para a Categoria 2:

Tabela 3 - Artigos da Categoria 2 - Fatores psicossociais e epidemiológicos (2016).

\begin{tabular}{|c|c|c|c|c|}
\hline Autor/Tema & Periódico/ Ano & Tipo de estudo & Amostra & Objetivos e Achados da Pesquisa \\
\hline $\begin{array}{l}\text { LOBATO, Gustavo; } \\
\text { MORAES, Claudia L; } \\
\text { e REICHENHEIM, } \\
\text { Michael E. Magnitude } \\
\text { da Depressão pós-parto } \\
\text { no Brasil: uma revisão } \\
\text { sistemática. }\end{array}$ & $\begin{array}{l}\text { Rev. Bras. Saúde } \\
\text { Matern. Infant. } \\
2011 .\end{array}$ & $\begin{array}{l}\text { Revisão Sistemática } \\
\text { da Literatura. }\end{array}$ & $\begin{array}{l}\text { Artigos científicos } \\
\text { publicados nas } \\
\text { bases de dados } \\
\text { Lilacs, Scielo e } \\
\text { Medline. }\end{array}$ & $\begin{array}{l}\text { O objetivo do trabalho foi realizar } \\
\text { uma revisão sistemática dos } \\
\text { estudos sobre a magnitude da } \\
\text { depressão pós-parto(DPP) no } \\
\text { Brasil. Foram selecionados } 14 \\
\text { estudos, sendo que } 13 \text { deles } \\
\text { reportavam a prevalência de DPP e } \\
\text { apenas um estudo de seguimento } \\
\text { com limitada casuística (n=21) } \\
\text { trazia estimativa da incidência do } \\
\text { agravo } \\
(42,8 \%) \text {. }\end{array}$ \\
\hline $\begin{array}{l}\text { MORAES, Maria de } \\
\text { Lima Salum; } \\
\text { FONSECA, Luiz } \\
\text { Augusto Marcodes; } \\
\text { DAVID; Vinicius } \\
\text { Frayze; e OTTA, } \\
\text { Emma. Fatores } \\
\text { psicossociais e } \\
\text { sociodemográficos } \\
\text { associados à depressão } \\
\text { pós-parto: um estudo } \\
\text { em hospitais publico e } \\
\text { privado da cidade de } \\
\text { São Paulo, Brazil. }\end{array}$ & $\begin{array}{l}\text { Estudos de } \\
\text { Psicologia, } 2015 .\end{array}$ & $\begin{array}{l}\text { Exploratório } \\
\text { Descriti-vo }\end{array}$ & $\begin{array}{l}462 \text { mulheres: } \\
205, \text { no hospital } \\
\text { público e } 257, \text { no } \\
\text { privado. }\end{array}$ & $\begin{array}{l}\text { O objetivo do trabalho foi avaliar e } \\
\text { efeito de fatores sociodemográficos } \\
\text { e psicossociais sobre a ocorrência } \\
\text { de DPP em mulheres cujos partos } \\
\text { ocorreram em dois hospitais da } \\
\text { cidade de São Paulo: um público e } \\
\text { outro privado. No hospital público, } \\
\text { a prevalência de DPP foi de } 26 \% \text { e, } \\
\text { no privado, de } 9 \% \text {.Análise de } \\
\text { regressão envolvendo } \\
\text { características psicossociais das } \\
\text { participantes revelou associação } \\
\text { positiva de DPP com depressão } \\
\text { anterior e com frequência de } \\
\text { conflitos com o parceiro e relação } \\
\text { negativa com anos de escolaridade } \\
\text { e escore de apoio social. }\end{array}$ \\
\hline $\begin{array}{l}\text { KONRADT, Caroline } \\
\text { Elizabeth; da SILVA, } \\
\text { Ricardo Azevedo; } \\
\text { JASEN, Karen; } \\
\text { VIANNA, Daniela }\end{array}$ & $\begin{array}{l}\text { Rev. Psiquiatr. } \\
\text { Rio Grande do } \\
\text { Sul, } 2011 .\end{array}$ & $\begin{array}{l}\text { Exploratório } \\
\text { Descriti-vo }\end{array}$ & $\begin{array}{l}1019 \text { gestantes } \\
\text { atendidas no } \\
\text { Sistema Único de }\end{array}$ & $\begin{array}{l}\text { O objetivo do trabalho foi } \\
\text { identificar o impacto da percepção } \\
\text { de baixo suporte social durante a } \\
\text { gestação como fator de risco para a } \\
\text { depressão no período de } 30 \text { a } 60\end{array}$ \\
\hline
\end{tabular}




\begin{tabular}{|c|c|c|c|c|}
\hline $\begin{array}{l}\text { Martins; QUEVEDO, } \\
\text { Luciana de Avila; }\end{array}$ & & & $\begin{array}{l}\text { Saúde na cidade } \\
\text { de Pelotas (RS). }\end{array}$ & $\begin{array}{l}\text { dias pós-parto. Das } 1.019 \text { mulheres } \\
\text { avaliadas, } 168(16,5 \%) \\
\text { apresentaram depressão pós-parto. } \\
\text { Aquelas que não receberam suporte } \\
\text { do companheiro } \\
(\mathrm{p}=0,000) \text {, de familiares }(\mathrm{p}= \\
0,000) \text { e de amigos }(\mathrm{p}=0,000) \\
\text { demonstraram maior risco de ter } \\
\text { depressão pós-parto. }\end{array}$ \\
\hline $\begin{array}{l}\text { SOUSA, Daniela } \\
\text { Delias de; PRADO, } \\
\text { Luiz Carlos; e } \\
\text { PICCININI, Cesar } \\
\text { Augusto. } \\
\text { Representações acerca } \\
\text { da maternidade no } \\
\text { contexto da Depressão } \\
\text { Pós-parto. }\end{array}$ & $\begin{array}{l}\text { Psicologia: } \\
\text { Reflexão e } \\
\text { Crítica, } 2011 .\end{array}$ & $\begin{array}{l}\text { Exploratório } \\
\text { Descriti-vo }\end{array}$ & $\begin{array}{l}\text { Duas famílias } \\
\text { cujas mães } \\
\text { Apresentavam } \\
\text { indicadores de } \\
\text { depressão } \\
\text { moderada. }\end{array}$ & $\begin{array}{l}\text { O trabalho teve como objetivo } \\
\text { investigar as representações acerca } \\
\text { da maternidade no contexto da } \\
\text { depressão pós-parto.Nos relatos de } \\
\text { ambas as mães apareceram } \\
\text { representações acerca do } \\
\text { sentimento de não ser capaz de } \\
\text { cuidar do bebê logo após o } \\
\text { nascimento, de ser pouco apoiada } \\
\text { pelo companheiro, bem como uma } \\
\text { reavaliação do relacionamento com } \\
\text { suas próprias mães e com seus } \\
\text { cônjuges. As representações de } \\
\text { cada mãe também apontaram para } \\
\text { uma estreita associação entre seus } \\
\text { conflitos pregressos e a interação } \\
\text { atual com o marido e com o bebê. }\end{array}$ \\
\hline $\begin{array}{l}\text { FIGUEIRA, Patrícia } \\
\text { Gomes; DINIZ, } \\
\text { Leandro Malloy; e da } \\
\text { SILVA FILHO, } \\
\text { Humberto Corrêa. } \\
\text { Características } \\
\text { demográficas e } \\
\text { psicossociais } \\
\text { associadas à depressão } \\
\text { pós-parto em uma } \\
\text { amostra em Belo } \\
\text { Horizonte. }\end{array}$ & $\begin{array}{l}\text { Rev. Psiquiatr } \\
\text { Rio Gd Sul, } \\
2011 .\end{array}$ & $\begin{array}{l}\text { Exploratório } \\
\text { Descriti-vo }\end{array}$ & $\begin{array}{l}245 \text { mulheres que } \\
\text { tiveram parto em } \\
\text { uma maternidade } \\
\text { de Belo } \\
\text { Horizonte. }\end{array}$ & $\begin{array}{l}\text { O objetivo do trabalho foi comparar } \\
\text { mulheres com e sem DPP em um } \\
\text { grupo de puérperas selecionadas } \\
\text { aleatoriamente a partir dos partos } \\
\text { ocorridos em uma maternidade de } \\
\text { Belo Horizonte (MG).Não foram } \\
\text { encontradas diferenças } \\
\text { sociodemográficas entre os grupos. } \\
\text { Mas diversas variáveis clínicas e } \\
\text { psicossociais se mostraram } \\
\text { diferentes nas mulheres com e sem } \\
\text { DPP, como a história de depressão, } \\
\text { vivência de estresse ou presença de } \\
\text { sintomas depressivos ou ansiosos } \\
\text { durante a gravidez, ocorrência de } \\
\text { complicações maternas ou na } \\
\text { criança no pós-parto e insuficiência } \\
\text { de suporte nos cuidados pós-natais. }\end{array}$ \\
\hline $\begin{array}{l}\text { ALVES, Stephanie; } \\
\text { FONSECA, Ana; } \\
\text { CANAVARRO, Maria } \\
\text { Cristina; e PEREIRA, } \\
\text { Marco. Que } \\
\text { mães/futuras mães } \\
\text { utilizam a internet para } \\
\text { questões relacionadas } \\
\text { com a saúde mental? }\end{array}$ & $\begin{array}{l}\text { Psicologia, saúde } \\
\text { e doenças, } 2016 .\end{array}$ & $\begin{array}{l}\text { Exploratório } \\
\text { Descriti-vo }\end{array}$ & $\begin{array}{l}546 \text { mulheres no } \\
\text { período perinatal } \\
\text { ( } 57 \% \text { no pós- } \\
\text { parto). }\end{array}$ & $\begin{array}{l}\text { O objetivo deste estudo foi } \\
\text { caracterizar o padrão de utilização } \\
\text { de Internet para questões } \\
\text { relacionadas com saúde e saúde } \\
\text { mental de mulheres no período } \\
\text { perinatal e analisá-lo em função de } \\
\text { características sociodemográficas, } \\
\text { clínicas e de literária em eHealth. } \\
\text { As participantes com história prévia } \\
\text { de problemas ou tratamento } \\
\text { psicológicos e psiquiátricos, } \\
\text { tratamento psicológico/psiquiátrico } \\
\text { atual, níveis superiores de } \\
\text { sintomatologia depressiva } \\
\text { reportaram maior probabilidade de } \\
\text { utilizar a internet para }\end{array}$ \\
\hline
\end{tabular}




\begin{tabular}{|l|l|l|l|}
\hline & & & $\begin{array}{l}\text { comportamentos de pesquisa de } \\
\text { informação e interação } \\
\text { relacionados com saúde mental. }\end{array}$ \\
\hline
\end{tabular}

Esta categoria, por ser a que mais se aproxima do objetivo principal deste trabalho, possui o maior número de artigos encontrados. Os fatores psicossociais tiveram estreita relação aos dados encontrados na categoria 1 , mostrando que os fatores de risco para a DPP foram identificados em puérperas diagnosticadas.

Foram apresentados como fatores psicossociais das mulheres com DPP: o baixo apoio dos familiares, a mudança na dinâmica familiar, a história de depressão ou de ansiedade, o sentimento de incapacidade e de medo (muitas vezes relacionadas aos cuidados com a criança e a amamentação) e a mudança na relação com o cônjuge e com as mães (MORAES ET. AL., 2015; KONRADT ET. AL., 2011; SOUSA, PRADO, PICCININI, 2011). Mulheres dentro dos sintomas de DPP e, principalmente que já tiveram episódio de depressão anterior, apresentam também comportamento de busca de informações na internet sobre saúde mental (ALVES, et. al., 2016).

No estudo de Moraes et. al. (2005) foi identificado outra variável presente em mulheres com DPP: terem seu parto realizado em hospital público e privado. O primeiro obteve maiores índices negativos sob o segundo no tocante ao desenvolvimento de DPP.

Quanto aos fatores sociodemográficos (idade, escolaridade, estado civil, etc.) não foram encontradas diferenças significativas entre mulheres com e sem DPP (FIGUEIRA; DINIZ; SILVA FILHO, 2011).

\section{Categoria 3 - Consequências da DPP}

A terceira categoria elencada neste estudo diz respeito às consequências que a depressão pós-parto pode ocasionar. Neste eixo temático foram identificados três trabalhos.

Entende-se por consequências da DPP todos os efeitos desta condição sobre a mãe, a criança e a família. Foram anexados trabalhos que abrangessem estes temas cujos dados estão expostos na Tabela 4. 
Tabela 4 - Artigos da Categoria 3 - Consequências da depressão pós-parto (2016).

\begin{tabular}{|c|c|c|c|c|}
\hline Autor/Tema & Periódico/ Ano & Tipo de estudo & Amostra & $\begin{array}{c}\text { Objetivos e Achados } \\
\text { da Pesquisa }\end{array}$ \\
\hline $\begin{array}{l}\text { CARLESO, Janaína } \\
\text { Pereira Pretto; } \\
\text { SOUZA, Ana Paula } \\
\text { Ramos; e MORAES, } \\
\text { Anaelena Bragança. } \\
\text { Análise da relação } \\
\text { entre depressão } \\
\text { materna e indicadores } \\
\text { clínicos de risco para o } \\
\text { desenvolvimento } \\
\text { infantil. }\end{array}$ & Rev. CEFAC. 2014 & $\begin{array}{l}\text { Exploratório } \\
\text { Descriti-vo }\end{array}$ & $\begin{array}{l}165 \text { díades mães- bebê } \\
\text { em Hospital Escola no } \\
\text { período de março a } \\
\text { maio de } 2010\end{array}$ & $\begin{array}{l}\text { O objetivo do trabalho } \\
\text { foi analisar as possíveis } \\
\text { correlações entre } \\
\text { alterações nos índices } \\
\text { de risco ao } \\
\text { desenvolvimento } \\
\text { linguístico e } \\
\text { psicológico do bebê e } \\
\text { presença de depressão } \\
\text { materna, em uma } \\
\text { amostra de mães de } \\
\text { bebês nascidos em } \\
\text { cidade de porte médio } \\
\text { e arredores da região } \\
\text { central do Rio Grande } \\
\text { do Sul. Comparando-se } \\
\text { bebês com e sem risco } \\
\text { ao desenvolvimento, } \\
\text { houve diferença } \\
\text { estatisticamente } \\
\text { significante, pois mães } \\
\text { com maiores escores } \\
\text { de depressão } \\
\text { apresentaram mais } \\
\text { risco ao } \\
\text { desenvolvimento de } \\
\text { seus filhos. }\end{array}$ \\
\hline $\begin{array}{l}\text { MACHADO, Mariana } \\
\text { Campos; ASSIS, } \\
\text { Karine Franklin; } \\
\text { OLIVEIRA, Fabiana } \\
\text { de Cássia Carvalho; } \\
\text { RIBEIRO, Andréia } \\
\text { Queiroz; ARAÚJO, } \\
\text { Raquel Maria Amaral; } \\
\text { CURY, Alexandre } \\
\text { Faisal; PRIORI, Silva } \\
\text { Heloisa; e } \\
\text { FRANCESCHINI, } \\
\text { Sylvia do Carmo } \\
\text { Castro. Determinantes } \\
\text { do abandono do } \\
\text { aleitamento exclusivo: } \\
\text { fatores psicossociais. }\end{array}$ & $\begin{array}{l}\text { Rev Saúde Pública, } \\
2014 .\end{array}$ & $\begin{array}{l}\text { Exploratório } \\
\text { Descriti-vo }\end{array}$ & $\begin{array}{l}168 \text { puérperas } \\
\text { provenientes da rede } \\
\text { pública de saúde em } \\
2011 / 2012 \text {. }\end{array}$ & $\begin{array}{l}\text { Teve o objetivo de } \\
\text { avaliar os } \\
\text { determinantes ao } \\
\text { abandono do } \\
\text { aleitamento materno } \\
\text { exclusivo. As } \\
\text { prevalências de } \\
\text { abandono do } \\
\text { aleitamento materno } \\
\text { exclusivo aos } 30,60 \text { e } \\
120 \text { dias após o parto } \\
\text { foram } 53,6 \% \text { (n = 90), } \\
47,6 \% \text { (n = 80) e } \\
69,6 \% \text { (n = 117), } \\
\text { respectivamente, e sua } \\
\text { incidência no quarto } \\
\text { mês em relação ao } \\
\text { primeiro foi } 48,7 \% \text {. } \\
\text { Sintomas de depressão } \\
\text { pós-parto e parto } \\
\text { traumático associaram- } \\
\text { se com abandono do } \\
\text { aleitamento materno } \\
\text { exclusivo no segundo } \\
\text { mês após o parto. }\end{array}$ \\
\hline
\end{tabular}




\begin{tabular}{|c|c|c|c|c|}
\hline $\begin{array}{l}\text { FIGUEIREDO, } \\
\text { Bárbara; DIAS, } \\
\text { Cláudia C.; } \\
\text { BRANDÃO, Sónia; } \\
\text { CANÁRIO, Catarina; e } \\
\text { NUNES-COSTA, Rui. } \\
\text { Amamentação e } \\
\text { depressão pós-parto: } \\
\text { revisão do estado de } \\
\text { arte. }\end{array}$ & J Pediatr (Rio J), 2013. & Revisão de literatura. & $\begin{array}{l}\text { Artigos encontrados na } \\
\text { base de dados } \\
\text { MEDLINE/Pub-Med. }\end{array}$ & $\begin{array}{l}\text { Objetivo de revisar a } \\
\text { literatura sobre a } \\
\text { associação entre a } \\
\text { amamentação e a } \\
\text { depressão } \\
\text { pós-parto. Observou-se } \\
\text { uma associação entre } \\
\text { amamentação e } \\
\text { depressão pós-parto, } \\
\text { não estando clara ainda } \\
\text { a direção dessa } \\
\text { associação. A } \\
\text { amamentação pode } \\
\text { promover processos } \\
\text { hormonais que } \\
\text { protegem as mães } \\
\text { contra a depressão pós- } \\
\text { parto por atenuar a } \\
\text { resposta do cortisol } \\
\text { ao estresse. }\end{array}$ \\
\hline
\end{tabular}

No que se refere às consequências produzidas pela DPP na mãe e na criança as pesquisas apontaram efeitos significativamente negativos na relação mãe-bebê. A tendência da mãe à melancolia, à tristeza, à apatia e ao sentimento de incapacidade de não conseguir cuidar da criança prejudica os primeiros contatos,que são considerados muito importantes para as relações futuras da criança, inclusive para a comunicação e o desenvolvimento linguístico (CALESSO, SOUSA, MORAES, 2014).

Figueiredo et. al. (2013) e Machado et. al. (2014) dedicaram seus estudos à questão da amamentação e da DPP. Foi encontrada uma associação entre desenvolvimento da DPP, o abandono do aleitamento e a amamentação como um fator protetor e de prevenção à DPP, mas estes dados ainda precisam ser analisados, segundo os autores.

Sobre a família e a mãe, pode-se observar semelhantes impactos. As expectativas criadas sobre a maternidade, que representa no imaginário um momento tranquilo e de pura felicidade, pode se contrapor à realidade e gerar um processo de frustração que vai demandar da família e da mãe a significação deste momento (CALESSO, SOUSA, MORAES, 2014). 
Id on Line Revista Multidisciplinar e de Psicologia

Id on Line Multidisciplinary and Psycology Journal

\section{Categoria 4 - Políticas de intervenção}

Esta categoria contempla os trabalhos que abordaram as políticas de intervenções nas mulheres acometidas com DPP.

Aqui são consideradas políticas de intervenção as ações abordadas pelos trabalhos encontrados que se voltam para o tratamento da depressão pós-parto, especialmente no âmbito da saúde coletiva.

Observou-se que nesta categoria havia poucas colocações e considerações sobre o tratamento da DPP, no entanto tais trabalhos focaram nos instrumentos de mapeamento da DPP, assim como nas práticas para abranger maior número de mulheres no tratamento.

A tabela 5, comporta os tais resultados alocados na Categoria 4.

Tabela 5 - Artigos da Categoria 4 - Políticas de Intervenção (2016).

\begin{tabular}{|c|c|c|c|c|}
\hline Autor/Tema & Periódico/ Ano & Tipo de estudo & Amostra & $\begin{array}{c}\text { Objetivos e Achados } \\
\text { da Pesquisa }\end{array}$ \\
\hline $\begin{array}{l}\text { MARTINEZ, Pablo; } \\
\text { VÖHRINGER, Paul } \\
\text { A.; ROJAS, Graciela. } \\
\text { Barreiras de acesso a } \\
\text { tratamento para mães } \\
\text { com depressão pós- } \\
\text { parto em centros de } \\
\text { atenção primária: um } \\
\text { modelo preditivo. }\end{array}$ & $\begin{array}{l}\text { Rev. Latino-Am. } \\
\text { Enfermagem, } 2016 .\end{array}$ & $\begin{array}{l}\text { Exploratório } \\
\text { Descriti-vo }\end{array}$ & $\begin{array}{l}\text { Mães que } \\
\text { participavam do } \\
\text { acompanhamento da } \\
\text { saúde da criança, do } \\
\text { segundo ao sexto mês } \\
\text { pós-parto, nos centros } \\
\text { de Atenção Primária. }\end{array}$ & $\begin{array}{l}\text { Objetivo do trabalho } \\
\text { foi desenvolver um } \\
\text { modelo preditivo para } \\
\text { avaliar os fatores que } \\
\text { modificam o acesso a } \\
\text { tratamento para a DPP. } \\
\text { Os resultados } \\
\text { encontrados apontam } \\
\text { que mães com DPP que } \\
\text { apresentem anedonia } \\
\text { (baixa/nula), } \\
\text { pânico/medo } \\
\text { escasso/nulo e sem } \\
\text { antecedentes de } \\
\text { depressão, tem maior } \\
\text { probabilidade de não } \\
\text { procurar o tratamento }\end{array}$ \\
\hline $\begin{array}{l}\text { ARRAES, Alessandra } \\
\text { da Rocha; MOURÃO, } \\
\text { Mariana Alves; } \\
\text { FRAGALLE, Bárbara. } \\
\text { O pré-natal psicológico } \\
\text { como programa de } \\
\text { prevenção à depressão } \\
\text { pós-parto. }\end{array}$ & $\begin{array}{l}\text { Saúde Soc. São Paulo, } \\
2014 .\end{array}$ & $\begin{array}{l}\text { Exploratório } \\
\text { Descriti-vo }\end{array}$ & $\begin{array}{l}\text { Foram colaboradoras } \\
\text { da pesquisa } 10 \\
\text { grávidas, } \\
\text { com idades entre } 23 \text { e } \\
33 \text { anos, captadas em } \\
\text { um serviço de } \\
\text { obstetrícia de um }\end{array}$ & $\begin{array}{l}\text { O objetivo da pesquisa } \\
\text { foi avaliar a } \\
\text { contribuição do PNP } \\
\text { para prevenir a DPP. } \\
\text { Encontrou-se que entre } \\
\text { o grupo intervenção a } \\
\text { ocorrência dos fatores } \\
\text { de risco superou a dos } \\
\text { fatores } \\
\text { de proteção e mais } \\
\text { metade desse grupo } \\
\text { evidenciou }\end{array}$ \\
\hline
\end{tabular}




\begin{tabular}{|c|c|c|c|c|}
\hline & & & $\begin{array}{l}\text { hospital privado de } \\
\text { Brasília. }\end{array}$ & $\begin{array}{l}\text { depressão gestacional, } \\
\text { mas não } \\
\text { desenvolveram a } \\
\text { DPP. Já no grupo } \\
\text { controle, duas } \\
\text { colaboradoras } \\
\text { apresentaram a DPP }\end{array}$ \\
\hline $\begin{array}{l}\text { SCHARDOSIM, } \\
\text { Juliana Machado; } \\
\text { HELDT, Elizeth. } \\
\text { Escalas de } \\
\text { rastreamento para a } \\
\text { depressão pós-parto. }\end{array}$ & $\begin{array}{l}\text { Rev Gaúcha Enferm. } \\
2011 .\end{array}$ & Revisão Sistemática. & $\begin{array}{l}\text { Foram incluídos } 18 \\
\text { artigos } \\
\text { nesta revisão } \\
\text { encontrados nas bases } \\
\text { de dados: Medline, } \\
\text { Scielo, Lilacs, Pubmed } \\
\text { e Adolec. }\end{array}$ & $\begin{array}{l}\text { O objetivo deste estudo } \\
\text { foi realizar uma revisão } \\
\text { sistemática sobre as } \\
\text { escalas de rastreamento } \\
\text { de Depressão Pós-Parto } \\
\text { (DPP) aplicadas até } 16 \\
\text { semanas após o parto } \\
\text { em puérperas acima de } \\
15 \text { anos. O período de } \\
\text { rastreamento de DPP } \\
\text { variou de } 2 \text { a } 10 \text { dias } \\
\text { pós-parto e o reteste } \\
\text { entre } 8 \text { e } 16 \text { semanas } \\
\text { pós-parto. A DPP foi } \\
\text { diagnosticada entre } 8,8 \\
\text { a } 40 \% \text { da amostra dos } \\
\text { estudos. A escala mais } \\
\text { utilizada foi a Edinburg } \\
\text { Depression Postpartum } \\
\text { Scale (EDPS). }\end{array}$ \\
\hline
\end{tabular}

A última categoria elenca as políticas de intervenção em mães com DPP. De acordo com Martinez, Vöhringer e Rojas (2016), apesar de haver grandes números de mães diagnosticadas com os sintomas de DPP, ainda são poucas as que mantém o tratamento (tendo como base os dados da atenção primária). Para os autores, é importante que os programas de intervenção foquem na DPP leve e nas mulheres que não possuam histórico de doença mental, visto que, segundo as pesquisas, este grupo tende a não procurar tratamento.

Fizeram parte desta categoria pesquisas que avaliaram escalas de rastreamento e de programas de combate à DPP, o desenvolvimento de escalas de rastreamento da DPP, assim como avaliação do programa. Segundo a pesquisa de Schardosim e Heldt (2011), o diagnóstico da DPP se dá em até 16 semanas após o parto. Já os estudos de Arraes, Mourão e Fragalle (2014) evidenciaram que grávidas que passaram pelo pré-natal psicológico (PNP) tiveram incidência de cinquenta por cento de depressão gestacional, no entanto não desenvolveram DPP. 
Id on Line Revista Multidisciplinar e de Psicologia

Id on Line Multidisciplinary and Psycology Journal

\section{Conclusões}

Este trabalho teve como objetivo principal realizar uma revisão sistemática da literatura sobre os aspectos psicossociais da Depressão Pós-Parto nos últimos cinco anos de publicações brasileiras (2011-2016). Os artigos foram analisados e categorizados de acordo com eixos temáticos, obedecendo assim os critérios dos objetivos específicos.

Observou-se, durante a revisão, que as pesquisas sobre DPP correlacionadas com os aspectos de cunho psicológico e social estavam divididas em quatro eixos temáticos, que neste trabalho foram chamados de categorias.

A primeira destas categorias contemplou os antecedentes da DPP, apontados basicamente como o histórico de algum tipo de transtorno psicológico, em especial depressão, a relação familiar e conjugal negativa, os problemas econômicos, a pouca idade e o uso de álcool e de outras drogas. A segunda categoria explicitou os fatores psicossociais e epidemiológicos da DPP, dentre estes fatores se destacaram: o pouco apoio da família durante os episódios depressivos, a prevalência de sentimentos de incapacidade, medo e culpa, além da mudança de comportamento em relação ao cônjuge.

As consequências da DPP formaram a terceira categoria desta pesquisa, os quais foram encontrados fatores prejudiciais tanto para a relação mãe-bebê como para a dinâmica familiar. Os bebês com mães depressivas podem ter impacto negativo sobre seu desenvolvimento, incluindo a linguagem e o afeto. $\mathrm{O}$ abandono do aleitamento também foi apontado como consequência.

O último ponto trata das políticas de intervenção, as ações de tratamento da DPP. Nesta categoria foi enfatizada a saúde pública, atentando para o último objetivo específico deste trabalho. Esta categoria deixou a desejar no que se refere às políticas desenvolvidas pelo Estado. Os trabalhos, que dela fizeram parte, enfatizaram as escalas de rastreamento e as avaliações de programas como o pré-natal psicológico.

Os trabalhos analisados foram predominantemente pesquisas empíricas, o que favorece a obtenção de um cenário para análise com amostras de todos os tamanhos e de várias partes do território brasileiro. No entanto, observa-se ainda a carência acerca de propostas de tratamento, em especial em saúde coletiva; e também avaliações de políticas já vigentes. 
Id on Line Revista Multidisciplinar e de Psicologia

Id on Line Multidisciplinary and Psycology Journal

Sugere-se que os trabalhos sobre o tema tomem tal direcionamento, para assim, tornam a explanação sobre a DPP mais completa.

Considera-se que os objetivos propostos para esta revisão foram alcançados, porém, este trabalho não pretende esgotar o tema em questão, mas levantar como as pesquisas estão direcionando outras sobre os aspectos psicológicos e sociais que circulam a depressão pósparto, coletando informações sistematizadas sobre a literatura.

\section{Referências}

AIROSA, Sara.; SILVA, I. Associação entre vinculação, ansiedade, depressão, estresse e suporte social na maternidade. Psicologia, saúde e doenças, Porto, 2013.

ALVES, S.; FONSECA, A.; CANAVARRO, M. C.; e PEREIRA, M.. Que mães /futuras mães utilizam a internet para questões relacionadas com a saúde mental. Psicologia, saúde e doenças, Coimbra, 2016.

ARRAIS, A. R.; MOURAO, M. A.; FRAGALLE, B. O pré-natal psicológico como panorama de prevenção a depressão pós-parto. Saúde Soc. São Paulo, v.23, 2014.

BARDIN, Laurence. Análise de conteúdo. Lisboa: Edições 70, 2002.

CALESSO, J. P. P.; SOUZA, A. P. R.; MORAES, A. B. Análise da relação entre depressão materna e indicadores clínicos de risco para o desenvolvimento infantil. Rev. CEFAC, Campinas, 2014.

CORRÊA, F. P.; SERRALHA, C. A. A depressão pós-parto e a figura materna: uma análise retrospectiva e contextual. Acta Colombiana de Psicología, São Paulo, 2015.

CUNHA, A. B. et al. A Importância do Acompanhamento Psicológico Durante a Gestação em Relação aos Aspectos que Podem Prevenir a Depressão Pós-Parto In Revista Saúde e Pesquisa, v. 5, n. 3, p. 579-586.set./dez, Maringá, 2012

DA-SILVA V. A .; MORAES-SANTOS A. R .; CARVALHO M. S .; MARTINS M. L., TEIXEIRA N. A .. Depressão pré-parto e pós-parto e a renda de mulheres brasileiras. Braz J Med Biol Res. Ribeirão Preto,1998.

DSM-IV. Manual Diagnóstico e Estatístico de Transtornos Mentais. 4 Edição Artmed, Porto Alegre. 1995. 
Id on Line Revista Multidisciplinar e de Psicologia

Id on Line Multidisciplinary and Psycology Journal

FIGUEIRA P.; CORREA H.; MALLOY-DINIZ L.; ROMANO-SILVA M. A.; Escala de Depressão Pós-natal para triagem no sistema público de saúde. Rev Saúde Pública. São Paulo, 2009.

FIGUEIRA, P. G.; DINIZ, L. M.; SILVA FILHO, H. C. Características demográficas e psicossociais associadas a depressão pós-parto em uma amostra de Belo Horizonte. Rev Psiquiatr Rio Gd Sul. 2011.

FIGUEIREDO, B.; DIAS, C. C.; BRANDÃO, S.; CANÁRIO, C.; e NUNES-COSTA, R. Amamentação e depressão pós-parto: revisão do estado de arte. $\mathrm{J}$ Pediatr (Rio J), 2013.

FRANCO, L. Equilíbrio e Saúde. Folha de São Paulo. São Paulo, 2016. Acesso em: 22. 08. 2016. Disponível em: http://m.folha.uol.com.br/equilibrioesaude/2016/05/1766064

FRIZZO, G. B.; PICCININI, C. A. Interação mãe-bebê em contexto de depressão materna: aspectos teóricos e empíricos. Psicologia em Estudo, Maringá, v. 10, 2005.

GALVÃO, T. F.; PEREIRA M. G. Revisões sistemáticas da literatura: passos para sua elaboração. Epidemiol. Serv. Saúde, Brasília, 2014

GONÇALVES, AC. A puérpera e o recém-nascido em alojamento conjunto. In: Oliveira DL, organizadora. Enfermagem na gravidez, parto e puerpério: notas de aula. Porto Alegre: Ed. da UFRGS; 2005. p. 367-86.

KHAN, K. S.; TER RIET, G.; GLANVILLE, J.; SOWDEN, A. J.; KLEIJNEN, J.; Centro NHS para Revisões e Difusão (CRD). Realização de Revisões Sistemáticas de Pesquisa sobre Eficácia. Centro NHS para Revisões e Divulgação da Universidade de York, 2000.

KLAUS, M. H.; KENNEL, J. H.; KLAUS, P. Vínculo: Construindo as bases para um apego seguro e para a independência. Porto Alegre, RS: Artes Médicas, 2000.

KONRADT, C. E.; SILVA, R. A.; JANSEN, K.; VIANNA, D. M.; QUEVEDO, L. A.; SOUZA, L. D. M.; OSES, J. P.; PINHEIRO, R. T. Depressão pós-parto e percepção de suporte social durante a gestação. Rev Psiquiatra, Rio Gd Sul. 2011.

LOBATO, G.; MORAES, C. L.; REICHENHEIM , M. E. Magnitude da depressão pós-parto no Brasil:uma revisão sistemática. Rev. Bras. Saúde Matern. Infant., Recife, 2011.

MACHADO, M. C. M.; ASSIS, K. F.; OLIVEIRA, F. C. C.; RIBEIRO, A. Q.; ARAUJO, R. M. A.; CURY, A. F.; PRIORI, S. E.; FRANCESCHINI, F. C. C. Determinantes do abandono do aleitamento materno exclusivo: fatores psicossociais. Rev Saúde Pública, São Paulo, 2014. 
Id on Line Revista Multidisciplinar e de Psicologia

Id on Line Multidisciplinary and Psycology Journal

MARTINEZ, P.; VÖHRINGER, P. A.; ROJAS, C. Barreiras de acesso a tratamento para mães com depressão pós-parto em centros de atenção primária: um modelo preditivo. Rev. Latino-Am. Enfermagem, Ribeirão Preto, 2016.

MINISTÉRIO DA SAÚDE (BR), Secretaria Executiva. Programa Humanização do Parto: humanização no pré-natal e nascimento. Brasília (DF); 2002.

MORAES, I. G. S. et al. Prevalência da depressão pós-parto e fatores associados. Rev. Saúde Pública Public Health, São Paulo, 2006.

MORAES, M. L. S.; FONSECA, L. A. M.; DAVID, V. F.; VIEGAS, L. M.; OTTA, E. Fatores psicossociais e sociodemográficos associados à depressão pós-parto: um estudo em hospitais público e privado da cidade de São Paulo, Brasil. Estudos de Psicologia, São Paulo, 2015.

OLIVEIRA, G. F.; BATISTA, H. M. T.; RUFATO, D. O.; MARANHÃO, T. L. G.; BRAGA, I. B.; GUEDES, J.B. Psicologia do trânsito: uma revisão sistemática. Caderno de Cultura e Ciência, v.13, n.2, Mar, Universidade Regional do Cariri - URCA, Crato, 2015.

PATINE F. S.; FURLAN, M. F. F. M. Diagnósticos de enfermagem no atendimento a puérperas e recém-nascidos internados em alojamento conjunto. Arq Ciênc Saúde.;13(4):202-8. 2006

RODRIGUES, O. M. P. R.; SCHIAVO, R. A. Stress na gestação e no puerpério: uma correlação com a depressão pós-parto. Rev. Brasileira de Ginecologia e Obstet., Bauru, 2011.

ROJAS G .; SOLIS J .; JADRESIC, E .; CASTILLO C .; GONZÁLEZ M .; GUAJARDO V., et ai. O tratamento da depressão pós-parto em mulheres de baixa renda em clínicas de cuidados primários em Santiago, Chile: um estudo controlado randomizado. Lancet., Londres, 2007.

ROSENBERG, J. L. Transtornos psíquicos da puerperalidade. In: BORTOLETTI, F. F. et al. Psicologia na prática obstétrica: abordagem interdisciplinar. Barueri: Manole, 2007.

SAMPAIO, R. F.; MANCINI, M. C. Estudos de revisão sistemática: um guia para síntese criteriosa da evidência científica. Rev. Brasileira de Fisioterapia, São Carlos, v.11, 2007.

SANTOS M. F. S.; MARTINS F. C.; PASQUALI L. Escalas de auto-avaliação de depressão pós-parto: um estudo no Brasil. Rev Psiquiatr Clin, São Paulo, 1999.

SANTOS, M. F. S. Depressão após o parto. 2001. Tese (Doutorado em Psicologia Clínica) Universidade de Brasília, Brasília, DF, 2001.

SANTOS, C. M. T.; ALMEIDA, G. O.; SOUZA, T. S. Depressão pós-parto: revisão da literatura. Psicologia em Foco, Frederico Westphalen, RS, 2009. 
Id on Line Revista Multidisciplinar e de Psicologia

Id on Line Multidisciplinary and Psycology Journal

SARMENTO, R.; LETÚBAL, M. S. V. Abordagem psicológica em obstetrícia: aspectos emocionais da gravidez, parto e puerpério. Rev. Ciências Médicas,Campinas, 2003.

SAÚDE. Organização Mundial da. CID-10 Classificação Estatística Internacional de Doenças e Problemas Relacionados à Saúde (10ª ed.). São Paulo: EDUSP, 2007.

SILVA, G.P.; MODESTO, José Fernando (Org.). Comunicação e produção científica. São Paulo: Angellara, 2006.

SILVA, F. C. S. et al. Depressão pós-parto em puérperas: conhecendo interações entre mãe, filho e família. Acta Paul Enfermagem, São Paulo, 2010.

SOUZA, A. I. et al. Alterações hematológicas e gravidez. Revista Brasileira Hematologia e Hemoterapia, São José do Rio Preto, v. 24, n.1, p. 29-36, mar. 2002.

SOUSA, D. D.; PRADO, L. C.; PICCININI, C. A. Representações acerca da maternidade no contexto da depressão pós-parto. Psicologia: Reflexão e Crítica, Porto Alegre, 2011.

STRAPASSON, M. R.; NEDEL, M. N. B. Puerpério imediato: desvendando o significado da maternidade. Rev Gaúcha Enfermermagem., Porto Alegre (RS) 2010 set;31(3):521-8. SCHARDOSIM, J. M.; HELDT, E.. Escalas de rastreamento para a depressão pós-parto. Rev Gaúcha Enferm., Porto Alegre, 2011.

TANNOUS L.; GIGANTE L. P.; FUCHS S. C.; BUSNELlO E. D.; Depressão no Sul do Brasil: prevalência e seus determinantes demográficos e socioeconômicos. BMC Psychiatry, Londres, 2008.

Como citar este artigo (Formato ABNT):

PORTO, Romenia A. F.; MARANHÃO, Thercia L. G.; FÉLIX, Waleska M. Aspectos Psicossociais da Depressão Pós-Parto: Uma Revisão Sistemática. Id on Line Revista Multidisciplinar e de Psicologia, Fevereiro de 2017, vol.11, n.34, p. 219-245. ISSN: 1981-1179.

Recebido: 06.02.2017

Aceito: 27.02.2017 